\title{
The validity of eight neoclassical facial canons in the Turkish adults
}

\author{
O. Karaca Saygili', S. Cinar ${ }^{2}$, B. Gulcen ${ }^{1}$, E. Ozcan ${ }^{1}$, I. Kus ${ }^{1}$ \\ ${ }^{1}$ Department of Anatomy, Faculty of Medicine, Balikesir University, Balikesir, Turkey \\ ${ }^{2}$ Department of Anatomy, Faculty of Medicine, KTO Karatay University, Konya, Turkey
}

[Received: 4 March 2016; Accepted: 18 April 2016]

\begin{abstract}
The neoclassical canons were used to define the proportions between various areas of the head and face. Therefore, this study was done to establish the neoclassical canons of facial proportions in Turkish adults. A total of 200 healthy adults 20 to 35 years of age were examined. Using anthropometric landmarks, 5 horizontal and 9 vertical direct measurements were made on the faces with a sliding calliper. Results have been compared with 8 neoclassical facial canons. When comparing between sexes, a significant difference has been found in all measurements except the upper facial width, left eye-fissure width, forehead height I and II $(p<0.005)$. The nasofacial proportion has been found to include the most proportional subjects (33\%) followed by the orbito-nasal (30\%), the orbital proportion (25\%) and the naso-oral proportion (17\%) in the female. Considering the male, the orbital proportion has been found to include the most proportional subjects (23\%) followed by the orbito-nasal proportion (21\%), naso-facial proportion (19\%) and the naso-oral proportion (17\%). The neoclassical canons have been shown to rarely be applicable to Turkish adults and our results may contribute to determine the concepts of transcultural facial structures. (Folia Morphol 2016; 75, 4: 512-517)
\end{abstract}

Key words: facial anthropometric norms, anthropometry, facial analysis

\section{INTRODUCTION}

The anatomical shape of the face varies depending on genetic factors, age and sex in among individuals. Until now, cephalographs, 2-dimensional photogrammetry and direct measurements were used to analyse the symmetry, shape and proportion of the anatomical structures of the face $[5,9,11,17]$. Anthropometry that uses the standard landmarks of the soft tissues in the face is a direct measurement method. Anthropometric studies show that there is a proportional relationship between standard landmarks of the face and these proportions are expressed as neoclassical canons $[1,4,16,18]$. The neoclassical canons used for proportional evaluation of the face were developed by artists and anatomists in the $17^{\text {th }}$ and $18^{\text {th }}$ centuries and these are defined as the aesthetic proportions of the face. The neoclassical canons have been used as reference by surgeons when planning the surgical treatment $[7,15]$. But data from several studies showed that there is a great diversity in the facial proportions among different ethnic groups and the neoclassical canons are insufficient to analyse the soft tissue of face in these groups $[1,4,16,18]$. Knowledge of anatomic facial structures of different societies is important for planning maxillofacial and reconstructive surgery. So, surgeons must consider population specific factors and make the appropriate adjustments when planning surgical or non-surgical treatments.

This study was conducted to investigate validity of the neoclassical canons for Turkish adults and to

Address for correspondence: Assist. Prof. Dr O. Karaca Saygili, Department of Anatomy, Faculty of Medicine, Balikesir University, Cagis Yerleskesi, 10145, Balikesir, Turkey, tel: +90-266-6121454, fax: +90-266-6121459, e-mail: omurkaraca@balikesir.edu.tr 
Table 1. Craniofacial anthropometric landmarks

\begin{tabular}{lccc}
\hline No. & Measurement names & Landmarks & Abbreviations \\
\hline 1 & Eye-fissure width & exocanthion-endocanthion & ex-en \\
2 & Intercanthal distance & endocanthion-endocanthion & en-en \\
3 & Upper facial width & zygion-zygion & zy-zy \\
4 & Nose width & alare-alare & al-al \\
5 & Mouth width & cheilion-cheilion & ch-ch \\
6 & Special head height & vertex-endocanthion & v-en \\
7 & Height of calvarium & vertex-trichion & v-tr \\
8 & Forehead height II & trichion-glabella & tr-g \\
9 & Forehead height II & trichion-nasion & tr-n \\
10 & Nose length & nasion-subnasale & n-sn \\
11 & Special upper face height & glabella-subnasale & g-sn \\
12 & Special face height & endocanthion-gnathion & en-gn \\
13 & Lower face height & subnasale-gnathion & sn-gn \\
14 & Ear length & superaurale-subaurale & sa-sba \\
\hline
\end{tabular}

establish the morphological characteristic of their faces by using anthropometry.

\section{MATERIALS AND METHODS}

This study was approved by the Ethic Committee of the Erciyes University, Turkey (Protocol No: 2009/177). Informed consent was obtained from all participants. The study participants included 200 healthy students and staff (100 females and 100 males) from the Nevsehir University. The participants were selected between the ages of 20 and 35 in order to reduce the effects of aging while calculating the facial proportions. Healthy volunteers were included in this study and body mass index was 20-25 for both sexes. The participants who had major facial trauma, craniofacial abnormalities and history of plastic and reconstructive surgery were excluded.

After determining the anthropometric landmarks, direct measurements were made by using a sliding calliper on the soft tissue of face. Fourteen standard anthropometric measurements were obtained (Table 1; Figs. 1, 2). The measurements were performed while subjects sitting on a chair in a relaxed mood and standard anthropometric methods were applied for all measurements. The measurements were taken as millimetres. The average values were compared with the neoclassical canons. Following 8 neoclassical canons were performed in Turkish adults. Two-section facial canon (vertex-endocanthion = endocanthiongnathion), three-section facial canon (trichion-nasion

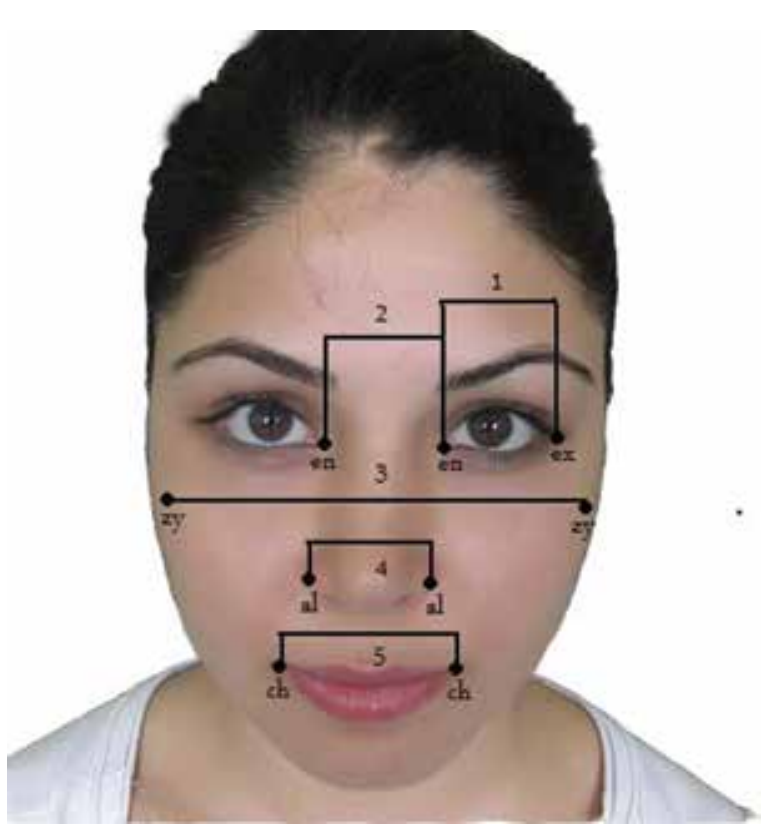

Figure 1. Anthropometric landmarks (1-5); al — alare; ch — cheilion; en — endocanthion; ex — exocanthion; zy — zygion.

= nasion-subnasale $=$ subnasale-gnathion), four-section facial canon (vertex-trichion = trichion-glabella $=$ glabella-subnasale = subnasale-gnathion), naso-aural canon (superaurale-subaurale = nasion-subnasale), naso-orbital canon (endocanthion-endocantion = alarealare), orbital canon (exocanthion-endocanthion = endocanthion-endocanthion), naso-oral canon ([alarealare] $\times 1.5=$ cheilion-cheilion) and naso-facial canon ([zygion-zygion] $\times 0.25=$ alare-alare) . 


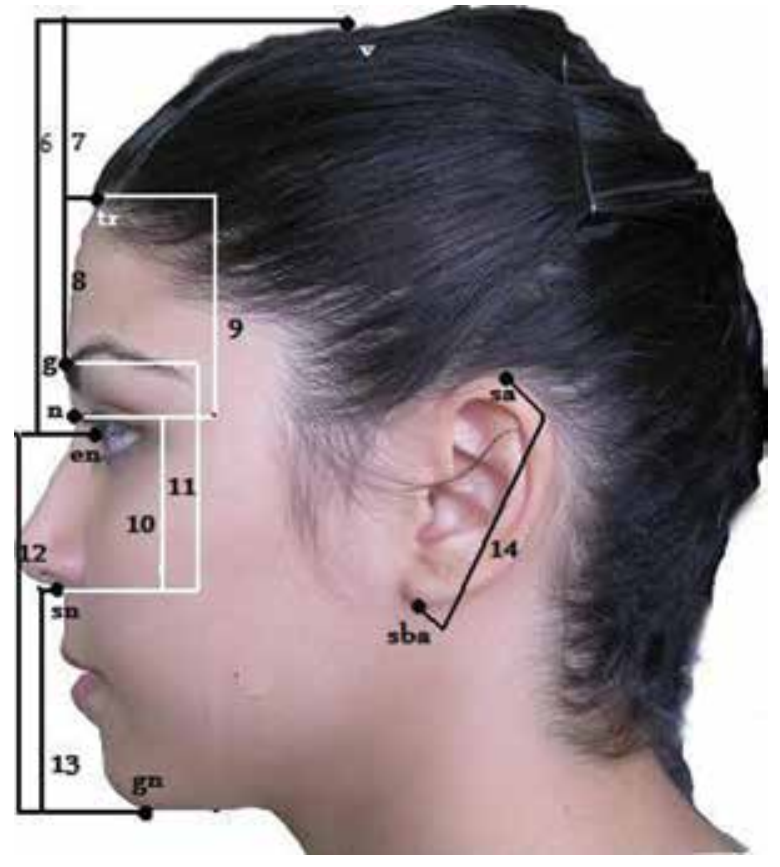

Figure 2. Anthropometric landmarks (5-14); g - glabella; gn gnathion; en - endocanthion; $\mathrm{n}$ - nasion; sa - superaurale; sba - subaurale; sn — subnasale; $\operatorname{tr}$ - trichion; $\mathrm{v}$ - vertex.

\section{Statistical analysis}

The findings of descriptive statistical parameters (mean, min. and max. values, and standard deviation) were calculated for the differences between the male and the female subjects. Independent T-test was used to analyse differences between the two groups (statistical package SPSS 15 for Windows). The statistical significance was set as $p<0.05$. A facial canon was considered valid if the difference is not bigger than $1 \mathrm{~mm}$.

\section{RESULTS}

In this study, comparisons revealed that all measurements were higher in the males and in both sexes the significant differences were observed in all parameters except the upper facial width, left eye-fissure width, forehead height I and II ( $p<0.005)$ (Table 2). In addition, 8 formulas for the neoclassical canons of the face were tested in Turkish adults and the results are showed in Table 3.

The results for canon I showed that the special head height measure was smaller than the special face height in the majority of our study groups ( $56 \%$ of females, $57 \%$ of males) and faces with the two-section profile was fitted in very few subjects ( $8 \%$ of females, $4 \%$ of males). Proportion for the three-section facial profile (canon II) was not seen in none of groups. The nose length was smaller than the lower facial height in $96 \%$ of females and in $100 \%$ of males. The forehead height II was smaller than the lower facial height in $35 \%$ of females and in $59 \%$ of males. The nose length was smaller than the lower facial height and the forehead height II in both of groups.

Table 2. The results of the craniofacial anthropometric measurements and independent samples $t$ test results between sexes

\begin{tabular}{|c|c|c|c|c|c|c|c|c|c|c|}
\hline \multirow[t]{2}{*}{ No. } & \multirow{2}{*}{$\begin{array}{l}\text { Measurements } \\
{[\mathrm{mm}]}\end{array}$} & \multicolumn{4}{|c|}{ Females $(n=100)$} & \multicolumn{4}{|c|}{ Males $(n=100)$} & \multirow[t]{2}{*}{$\mathbf{P}^{*}$} \\
\hline & & Min. & Max. & Mean & SD & Min. & Max. & Mean & SD & \\
\hline 1 & ex-en (left) & 28.50 & 38.21 & 33.39 & 1.84 & 27.01 & 38.35 & 33.91 & 2.30 & $<0.082$ \\
\hline 2 & en-en & 26.95 & 38.07 & 31.86 & 2.36 & 27.53 & 41.44 & 33.17 & 2.79 & $<0.000^{\mathrm{a}}$ \\
\hline 3 & $z y-z y$ & 111.19 & 141.58 & 127.20 & 6.54 & 115.06 & 145.45 & 129.06 & 7.08 & $<0.055$ \\
\hline 4 & al-al & 24.22 & 39.57 & 32.32 & 2.71 & 28.94 & 40.85 & 35.15 & 2.92 & $<0.000^{\mathrm{a}}$ \\
\hline 5 & ch-ch & 39.87 & 64.74 & 48.88 & 3.92 & 43.09 & 62.24 & 51.55 & 4.06 & $<0.000^{\mathrm{a}}$ \\
\hline 6 & v-en & 78.12 & 123.31 & 101.56 & 9.86 & 85.09 & 137.22 & 109.70 & 10.81 & $<0.000^{\mathrm{a}}$ \\
\hline 7 & v-tr & 15.47 & 47.93 & 29.04 & 7.63 & 10.47 & 58.59 & 33.32 & 11.47 & $<0.002^{\mathrm{a}}$ \\
\hline 8 & tr-g & 36.15 & 69.17 & 51.29 & 7.57 & 29.76 & 84.74 & 52.72 & 9.60 & $<0.224$ \\
\hline 9 & $\operatorname{tr}-n$ & 46.15 & 93.61 & 66.93 & 8.13 & 42.71 & 95.76 & 68.80 & 9.61 & $<0.140$ \\
\hline 10 & $\mathrm{n}$-sn & 42.78 & 60.27 & 50.36 & 3.74 & 40.07 & 62.92 & 53.14 & 4.41 & $<0.000^{a}$ \\
\hline 11 & g-sn & 58.03 & 79.84 & 69.21 & 4.51 & 61.42 & 87.60 & 73.46 & 5.13 & $<0.000^{\mathrm{a}}$ \\
\hline 12 & en-gn & 93.66 & 119.85 & 104.05 & 5.36 & 96.33 & 129.67 & 113.17 & 6.50 & $<0.000^{\mathrm{a}}$ \\
\hline 13 & sn-gn & 45.33 & 76.64 & 63.44 & 5.88 & 56.57 & 81.40 & 70.54 & 5.58 & $<0.000^{\mathrm{a}}$ \\
\hline 14 & sa-sba & 49.39 & 70.55 & 58.81 & 4.29 & 50.56 & 70.79 & 61.49 & 4.80 & $<0.000^{\mathrm{a}}$ \\
\hline
\end{tabular}

*Independent t-test, $\mathrm{p}<0.05$; aStatistically significant difference; min. — minimum; max. — maximum; SD — standard deviation; rest abbreviations as in Table 1 
Table 3. The neoclassical facial canon measurements in Turkish adults

\begin{tabular}{lcc}
\hline Neoclassical canon category & $\begin{array}{c}\text { Females } \\
\text { ( } \mathbf{n = 1 0 0 ) ; ~} \%\end{array}$ & $\begin{array}{c}\text { Males } \\
(\mathbf{n}=100) ; \%\end{array}$ \\
\hline Two-section facial profile & & \\
v-en $=$ en-gn & 8 & 4 \\
v-en $>$ en-gn & 36 & 39 \\
v-en < en-gn & 56 & 57 \\
\hline
\end{tabular}

\begin{tabular}{|c|c|c|}
\hline \multicolumn{3}{|l|}{ Three-section facial profile } \\
\hline $\mathrm{tr}-\mathrm{n}=\mathrm{n}-\mathrm{sn}=\mathrm{sn}-\mathrm{gn}$ & 0 & 0 \\
\hline n-sn $<$ sn-gn & 96 & 100 \\
\hline tr-n $>$ n-sn & 95 & 95 \\
\hline tr-n $<$ sn-gn & 35 & 59 \\
\hline tr-n > sn-gn & 57 & 36 \\
\hline \multicolumn{3}{|l|}{ Horizontal } \\
\hline$v-\operatorname{tr}=\operatorname{tr}-\mathrm{g}=\mathrm{g}-\mathrm{sn}=\mathrm{sn}-\mathrm{gn}$ & 0 & 0 \\
\hline $\mathrm{v}$-tr $<$ tr-g & 97 & 85 \\
\hline v-tr $>$ tr-g & 3 & 13 \\
\hline v-tr $<$ g-sn & 100 & 100 \\
\hline v-tr < sn-gn & 100 & 99 \\
\hline tr-g < sn-gn & 92 & 96 \\
\hline g-sn > sn-gn & 71 & 65 \\
\hline g-sn $<$ sn-gn & 21 & 25 \\
\hline \multicolumn{3}{|l|}{ Naso-aural } \\
\hline $\mathrm{n}-\mathrm{sn}=\mathrm{sa}-\mathrm{sba}$ & 1 & 4 \\
\hline n-sn > sa-sba & 3 & 6 \\
\hline n-sn $<$ sa-sba & 96 & 90 \\
\hline
\end{tabular}

\begin{tabular}{lll}
\hline Naso-orbital & 30 & 21 \\
en-en = al-al & 29 & 20 \\
en-en > al-al & 41 & 58 \\
en-en < al-al & & \\
\hline Orbital & 25 & 23 \\
en-en $=$ ex-en & 21 & 28 \\
en-en > ex-en & 54 & 49 \\
en-en < ex-en & & \\
\hline Naso-oral & 17 & 17 \\
ch-ch $=1.5$ (al-al) & 40 & 31 \\
ch-ch > 1.5 (al-al) & 43 & 52 \\
ch-ch < 1.5 (al-al) & & \\
\hline Naso-facial & 33 & 19 \\
al-al $=0.25$ (zy-zy) & 39 & 73 \\
al-al. $>0.25$ (zy-zy) & 33 & 8 \\
al-al. < 0.25 (zy-zy) & &
\end{tabular}

Abbreviations as in Table 1
Proportional equality for four equal profile sections (canon III) was not seen in our subjects. The height of the calvarium was smaller than all other canon measures (forehead height I, special upper facial height, lower facial height) in most of the subjects. The special upper facial height was greater than the lower facial height in $71 \%$ of females and in $65 \%$ of males. The forehead height $I$ and the height of the calvarium were smaller than the lower facial height (females/males: smaller the forehead height I 92\%/96\%; smaller the height of the calvarium 100\%/99\%).

Naso-aural proportion (canon IV) was found in 1\% of females and in $4 \%$ of males. Our most subjects had an ear length that was bigger than their nose length in $96 \%$ of females and in $90 \%$ of males. Assessment of naso-orbital proportion (canon V) showed that the nose width was equal to the intercanthal distance in $30 \%$ of females and in $21 \%$ of males. Most subjects had a greater the nose width than the intercanthal distance.

When we evaluated our results according to the orbital proportion (canon VI), the left eye-fissure length was equal to the intercanthal width in $25 \%$ of females and in $23 \%$ of males. The left eye-fissure length was greater than the intercanthal width in $54 \%$ of females and $49 \%$ of males. Naso-oral proportion (canon VII) was found in $17 \%$ of females and males. The 1.5 times the nose width was wider than the mouth width in $43 \%$ of females and in $52 \%$ of males. Evaluation of naso-facial proportion (canon VIII) showed that the nose width was equal to the facial width in $33 \%$ of females and in 19\% of males. The nose width was larger than the facial width of $39 \%$ of females and in $73 \%$ of males.

Our results with the eight neoclassical canons of face revealed that very few Turkish males fitted the established proportions. Whereas more Turkish females fitted the neoclassical canons compared with Turkish males.

\section{DISCUSSION}

The neoclassical canons were used to define the proportions between various areas of the head and face. And these facial cannons have been recommend in current text books on orthodontics, prosthodontics and plastic and reconstructive surgery for the treatment planning. Most of anthropometric data about the neoclassical canons comes from Farkas' work on North American white populations $[6,7,10,15]$. But another studies of Korean [4], Indian [12], African American [18], Turkish [2, 3] and Chinese [13] subjects as well as the present study, reported that some of the 
neoclassical canons may fit a few subjects and they do not represent the average facial proportions. In our study, especially the three-section and the four-section facial proportion could not be found valid even in a single participant. The naso-orbital canon was the most frequently observed canon in females while the orbital canon was the most applicable in males.

The results for vertical canon (canon I) showed that the special face height was greater than the special head height for both males and females in the current study. Whereas special face height was shorter than the special head height for both males and females in African American and North American white people $[6,18,19]$. In addition, when we compare our results for canon I with findings that were obtained from other studies in Turkish population the differences were seen between findings [2,3]. The results show that there may be differences in the facial proportions even in different regions of the same country.

The three-section facial proportion could not be found even in a single participant in this study. The forehead height II was greater than the lower face height in females $(57 \%)$ and in males ( $36 \%)$. In similar to our findings in another study the forehead height II was greater than the lower face height in African American females (63\%) and males (39\%) [18, 19]. However, it was shown that forehead height II was shorter than the lower face height in North Americans $[1,7]$. Some studies found that lower face heights was greater than the upper face heights in North American white females (68\%), Korean American females (42\%), and Indian Americans (37\%), African American males (98\%) and females (75\%) $[4,6,12$, 19]. Contrary to these findings that were obtained from other studies, the lower face height was greater than the upper face heights only in $21 \%$ of females and in $25 \%$ of males in our study.

Our results, according to the nasoaural canon (canon IV), were similar to the naso-aural canon analysis results of African American people, North American white people, Indian American and Korean American females $[4,6,12]$. In these studies, the ear length was greater than nose length in most subjects.

In terms of the naso-orbital canon, $41 \%$ of North American white people validated the naso-orbital canon, which states that the nose width equals the intercanthal distance [6]. In our study the nose width was equal to the intercanthal distance in $30 \%$ of fe- males and in $21 \%$ of males. The descriptive analysis results for naso-orbital canon showed that the intercanthal distance was shorter than the nose width for males (58\%) and females ( $41 \%)$ in the current study, in African American people (99\% of males, $93 \%$ of females), in North American white females (38\%) and in Indian American females (86\%) $[6,12,18]$. In the Asian people, the intercanthal distance was greater than the nose width in Korean American females $(61 \%)$ and in Southern Chinese people ( $56 \%$ of males, $90 \%$ of females) $[4,13]$.

The orbital canon purports that the width of the eye fissure should be equivalent to the intercanthal distance, and this fitted in $25 \%$ of females and in $23 \%$ of males in our samples. Similarly, $33 \%$ of North American white females, $21 \%$ of Indian American females, $30 \%$ of African American females validated the orbital canon $[12,18]$. For some Turkish adults the eye fissure length was greater ( $54 \%$ of females, $49 \%$ of males) than the intercanthal distance. The similar results were also found in Africans (42\%) [18] and in another study for Turkish population [3]. In contrast to our findings, Korean American females (100\%), Southern Chinese people $(100 \%)$ and North American white people $(52 \%)$ have intercanthal distance greater than eye widths $[4,6,13]$. The dominant characteristics of the Asian face type include a long intercanthal distance and a short palpebral fissure connection $[14,16]$.

According to the results obtained from the naso-oral proportions, the nose width was 1.5 times wider than the mouth width in Turkish adults (43\% of females, $52 \%$ of males), in Korean American females $(68 \%)$, in Southern Chinese people $(87 \%)$ and in African American females (87\%) $[4,13,19]$. Narrow mouth with wide nose variant of the naso-oral proportion was common among all the East Asian ethnic groups and the African Americans. While these people have narrow mouth with wide nose, majority of the North American white females (60\%) have wide mouth and narrow nose [6]. Similar to naso-oral proportion, the nose width was wider than one quarter of the facial width in most subjects in this study. Our results were similar to facial analysis results of African American people, Indian American and Korean American females $[4,12,18]$. Our findings show that contrast results of naso-facial proportions of North American white people. In another study, the nose was very or extremely significantly wide in both sexes of Asian and Black ethnic groups [8]. 


\section{CONCLUSIONS}

In conclusion, the applicability of the neoclassical canons was tested in our study. It was found that these canons were not applicable to most of Turkish adults. Thus these facial proportions cannot be a guide for planning surgical or non-surgical treatments. The knowledge of the facial characteristic of Turkish adults is important to compare the facial soft tissues before and after treatment.

\section{Acknowledgements}

The authors thank to Dr. Fatma Bahar Sunay from University of Balikesir, Faculty of Medicine, Department of Histology and Embryology, Turkey for final linguistic revision of the manuscript.

\section{REFERENCES}

1. Arslan S, Genç C, Odabaş B, Kama J (2008) Comparison of facial proportions and anthropometric norms among Turkish young adults with different face types. Aesth Plast Surg, 32: 234-242.

2. Borman H, Ozgur F, Gursu G (1999) Evaluation of softtissue morphology of the face in 1,050 young adults. Ann Plast Surg, 42: 280-288.

3. Bozkir MG, Karakas P, Oguz O (2004) Vertical and horizontal neoclassical facial canons in Turkish young adults. Surg Radiol Anat, 26: 212-219.

4. Choe KS, Sclafani AP, Litner JA, Yu GP (2004) The Korean American woman's face: anthropometric measurements and quantitative analysis of facial aesthetics. Arch Facial Plast Surg, 6: 244-252.

5. Farkas LG (1981) Anthropometry of the head and face in medicine. Elsevier. New York.

6. Farkas LG, Hreczko TA, Kolar JC, Munro IR (1985) Vertical and horizontal proportions of the face in young adult North American Caucasians: revision of neoclassical canons. Plast Reconstr Surg, 75: 328-338.

7. Farkas LG (1994) Anthropometry of the head and face. 2. Raven press, New York.
8. Farkas LG, Forrest CR, Litsas L (2000) Revision of neoclassical facial canons in young adult Afro-Americans. Aesth Plast Surg, 24: 179-184.

9. Farkas LG, Tompson BD, Katic MJ, Forrest CR (2002) Differences between direct (anthropometric) and indirect (cephalometric) measurements of the skull. J Craniofac Surg, 13: 105-108.

10. Farkas LG, Katic MJ, Forrest CR (2005) International anthropometric study of facial morphology in various ethnic groups/races. J Craniofac Surg, 16: 615-646.

11. Ghoddousi $H$, Edler R, Haers $P$, Wertheim $D$, Greenhill $D$ (2007) Comparison of three methods of facial measurement. Int J Oral Maxillofac Surg, 36: 250-258.

12. Husein OF, Sepehr A, Garg R, Sina- Khadiv M, Gattu S, Waltzman J, Wu EC, Shieh M, Heitmann GM, Galle SE (2010) Anthropometric and aesthetic analysis of the Indian American woman's face. J Plast Reconstr Aesthet Surg, 63: 1825-1831.

13. Jayaratne YS, Deutsch CK, McGrath CP, Zwahlen RA (2012) Are Neoclassical Canons Valid for Southern Chinese Faces? PloS One, 7: 1-7.

14. Le TT, Farkas LG, Ngim RCK, Levin LS, Forrest CR (2002) Proportionality in Asian and North American Caucasian faces using neoclassical facial canons as criteria. Aesth Plast Surg, 26: 64-69.

15. Lehmann JA (1987) Soft tissue manifestations of aesthetic defects of the jaws: diagnosis and treatment. Clin Plast Surg, 14: 767-783.

16. Ngeow WC, Aljunid ST (2009) Craniofacial anthropometric norms of Malaysian Indians. Indian J Dent Res, 20: 313-319.

17. Ozdemir MB, llgaz A, Dilek A, Ayten H, Esat A (2007) Describing normal variations of head and face by using standard measurement and craniofacial variability index (CVI) in seven-year-old normal children. J Craniofac Surg, 18: 470-474.

18. Porter JP, Olson KL (2001) Anthropometric facial analysis of the African American woman. Arch Facial Plast Surg, 3: 191-197.

19. Porter JP (2004) The average African American male face an anthropometric analysis. Arch Facial Plast Surg, 6: 78-81. 